\title{
Prediction of chronic lung allograft dysfunction: a systems medicine challenge
}

\author{
Christophe Pison $1,2,3,4$, Antoine Magnan ${ }^{5,6}$, Karine Botturi, ${ }^{5,6}$, Michel Sève ${ }^{7,8}$, \\ Sophie Brouard ${ }^{5,6}$, Benjamin J. Marsland ${ }^{9,10}$, Florian Ernst ${ }^{11}$, Tobias Paprotka ${ }^{11}$, \\ Kevin Deplanche ${ }^{12}$, Andreas Fritz ${ }^{13}$, Valérie Siroux ${ }^{14}$, Jean-Pierre Boissel ${ }^{15}$, \\ Paul A. Corris ${ }^{16}$, Charles Auffray ${ }^{17}$ and Laurent P. Nicod ${ }^{9,10}$ on behalf of the \\ SysCLAD consortium ${ }^{18}$
}

\begin{abstract}
Affiliations: ${ }^{1}$ Clinique Universitaire de Pneumologie, Pôle de Cancérologie, Médecine Aiguë et Communautaire, CHU Grenoble, ${ }^{2}$ Inserm1055, Grenoble, ${ }^{3}$ Université Joseph Fourier, Grenoble, ${ }^{4}$ European Institute for Systems Biology and Medicine, EISBM, Lyon, ${ }^{5}$ Institut du Thorax, Inserm UMR1087, CNRS UMR629, Service de Pneumologie, CHU de Nantes DHU2020, Nantes, ${ }^{6}$ Université de Nantes, Nantes, ${ }^{7}$ Université Joseph Fourier, Institut Albert Bonniot, Inserm 823, CHU Grenoble, ${ }^{8}$ Prométhée Proteomics Platform, Grenoble, ${ }^{12}$ Finovatis, Lyon, ${ }^{14}$ Université Joseph Fourier, Inserm U823, Centre de recherche Albert Bonniot, Equipe d'Epidémiologie Environnementale appliquée à la Reproduction et la Santé Respiratoire, Grenoble, ${ }^{15}$ Novadiscovery, Lyon, and ${ }^{17}$ European Institute for Systems Biology and Medicine, CNRS, UCBL, ENS, Université de Lyon, Lyon, France. 'Service de Pneumologie, Centre Hospitalier Universitaire Vaudois, Lausanne, and ${ }^{10}$ Université de Lausanne, Lausanne, Switzerland. ${ }^{11}$ GATC Biotech AG, Konstanz, and ${ }^{13}$ Biomax Informatics AG, Planegg, Germany. ${ }^{16}$ Institute of Transplantation, Institute of Cellular Medicine, Medical School, Newcastle University, Newcastle upon Tyne, UK. ${ }^{18}$ For a full list of the the SysCLAD consortium members, see the Acknowledgements section.
\end{abstract}

Correspondence: C. Pison, Pôle de Cancérologie, Médecine Aiguë et Communautaire, Clinique Universitaire de Pneumologie, Centre Hospitalier et Universitaire de Grenoble, BP 217 X, 38043 Grenoble, Cedex 9, France. E-mail: CPisondachu-grenoble.fr

@ERSpublications

CLAD prediction: a systems medicine approach to improve knowledge to aid early intervention prior to lung function decline http://ow.ly/rNFMH

The International Society for Heart and Lung Transplantation registry recorded that 3631 adult heart-lung transplants and 39835 adult lung transplants have been performed in centres throughout the world up to 2012, establishing lung transplantation (LT) as the standard of care for selected patients with end-stage respiratory disease [1]. The long-term success of LT is limited by chronic lung allograft dysfunction (CLAD), of which the two most common phenotypes are an abnormal remodelling of the small airways resulting in progressive airflow obstruction called bronchiolitis obliterans syndrome (BOS) and, less frequently, a restrictive ventilatory process referred to as restrictive allograft syndrome (RAS) [2, 3]. Almost $50 \%$ of LT recipients will develop CLAD within 5 years post-LT, rising to $75 \%$ after 10 years [1]. Despite a range of therapeutic approaches, median survival figures from the time of diagnosis remain very poor at $\sim 2$ years, resulting in $27 \%$ overall 10-year survival, the poorest long-term survival after solid-organ transplantations for the period of 2000-2008 in the USA [4].

In clinical practice, CLAD is a diagnosis of exclusion once the possible confounding diseases related either to allograft, such as persistent acute rejection, azithromycin-reversible allograft dysfunction, infection, anastomotic stricture, disease recurrence, and/or to extra-allograft complications, such as pleural disease,

Received: Sept 152013 | Accepted after revision: Nov 202013

Clinical trial: This study is registered at www.ClinicalTrials.gov with identifier NCT00980967.

Support statement: The SysCLAD study is an EU-funded project, HEALTH-F5-2012, grant agreement No. 305457 under the Seventh Framework Programme (FP7).

Conflict of interest: Disclosures can be found alongside the online version of this article at www.erj.ersjournals.com

Copyright @ERS 2014 
diaphragm dysfunction or native lung hyperinflation, have been ruled out. CLAD diagnosis relies on persistent and irreversible decline $\geqslant 20 \%$ in post-bronchodilator mean of two best forced expiratory volume in $1 \mathrm{~s}$ (FEV1) and/or forced vital capacity (FVC) measurements for $>3$ weeks, accordingly to a new proposed classification for CLAD. [3]. Pulmonary functional tests are used to define CLAD since pathology samplings display important limitations [3]. Treating CLAD remains a challenge because underlying molecular events and triggers are not well understood and unfortunately are irreversible. An early prediction of CLAD, different from an early diagnosis, founded on the principles of systems biology and personalised medicine would represent a major breakthrough, characterised by early interventions based on risk stratification and personalised pathway modulation and would undoubtedly improve the clinical outcomes [5, 6]. Regarding biomarkers in solid-organ transplantation, after more than 15000 studies, only two diagnostic tests are US Food and Drug Administration approved and none in the context of early CLAD prediction [5]. By 2013, there are no tools to predict medium outcomes after solid-organ transplantation apart from retrospective analyses of registries, based mostly on clinical data from donors and recipients with poor calibration far away from personalised medicine $[1,7]$. Numerous and different explanations can be put forward to explain such a failure in registered biomarkers in solid-organ transplantation [8] and include: nonconsensus definition of CLAD; actual complexity of CLAD mechanisms; paucity of large prospective multicentre cohorts with controlled clinical data on donors and recipients; inadequate quality control of biospecimen acquisition, processing, storage; erratic standardisation of pre-analytical and analytical conditions; incompatible formats for data capture; lack of repeated samplings; lack of data from multiple platforms including D/R human leukocyte antigen (HLA) characterisations, epigenetic (microRNA) and genotype analyses (single-nucleotide polymorphism (SNP) discovery, using exome sequencing, will permit the discovery of new intrinsic risks that are connected to the development of either BOS or RAS or both), transcriptomics, protein, peptides and metabolite profiling studies; and ultimately failure to integrate and model multiple heterogeneous data types.

In an attempt to better predict CLAD before irreversible damage occurs within the graft, a multidisciplinary consortium Systems prediction of CLAD (SysCLAD) was set up with 14 lung transplantations centres, four small and medium enterprises, and three academic platforms and was funded by the European Union under the Seventh Framework Programme. The objective of SysCLAD is to build a computational model in order to estimate, within the first year post-LT, a personal recipient risk of CLAD at 3 years, a timeframe associated with the worst vital prognosis [9]. This prediction will be derived from the complete integration of extensive and diverse experimental datasets (clinicome, environmental data, omics, microbiome, and immunological assays) collected from both donors and recipients (table 1). The project relies on a prospective cohort of LT recipients as an expansion of the already existing French Cohort Of Lung Transplantation (COLT) (http://clinicaltrials.gov/ identifier: NCT00980967), which has recruited 827 LT recipients between September 2009 and August 2013. Standardised Operating Procedures (SOP) from

TABLE 1 Data collection within the first year post-lung transplantation (LT) to predict chronic lung allograft dysfunction (CLAD) at year 3

\section{Pre-LT Day 0, lung 6 months post-LT 12 months post-LT procurement and LT}

\begin{tabular}{|c|c|c|c|}
\hline Donor & & $\begin{array}{l}\text { Sex, age, comorbidities, } \\
\text { gas exchange, HLA }\end{array}$ & \\
\hline $\begin{array}{l}\text { Recipient } \\
\text { clinicome }\end{array}$ & $\begin{array}{l}\text { Sex, underlying } \\
\text { diagnosis } \\
\text { conducting to LT }\end{array}$ & $\begin{array}{l}\text { Age, cold ischaemic } \\
\text { time, ischaemia- } \\
\text { reperfusion issue, } \\
\text { centre effect }\end{array}$ & $\begin{array}{l}\text { Home geolocalisation, rejection, infection episodes, bronchial } \\
\text { complications, immunosuppressive regimen, lung function } \\
\text { Outcomes at } 3 \text { years: healthy, RAS, BOS, deceased }\end{array}$ \\
\hline Blood studies & $\begin{array}{l}\text { Transcriptomics, } \\
\text { HLA, HLA } \\
\text { antibodies }\end{array}$ & & 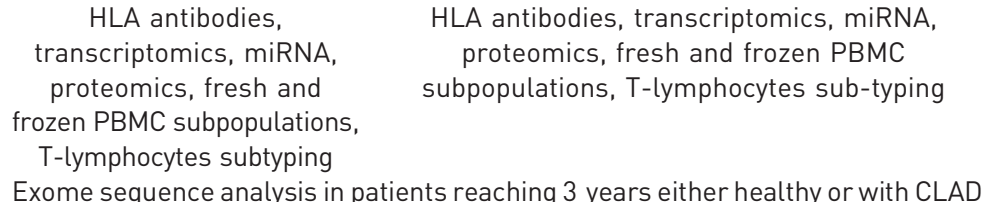 \\
\hline BAL studies & & & $\begin{array}{c}\text { Cell counts, proteomics, } \\
\text { microbiote, macrophages } \\
\text { subpopulations }\end{array}$ \\
\hline
\end{tabular}

BAL: bronchoalveolar lavage; HLA: human leukocyte antigen; RAS: restrictive allograft syndrome; BOS: bronchiolitis obliterans syndrome; miRNA: microRNA; PBMC: peripheral blood monocyte cells. 


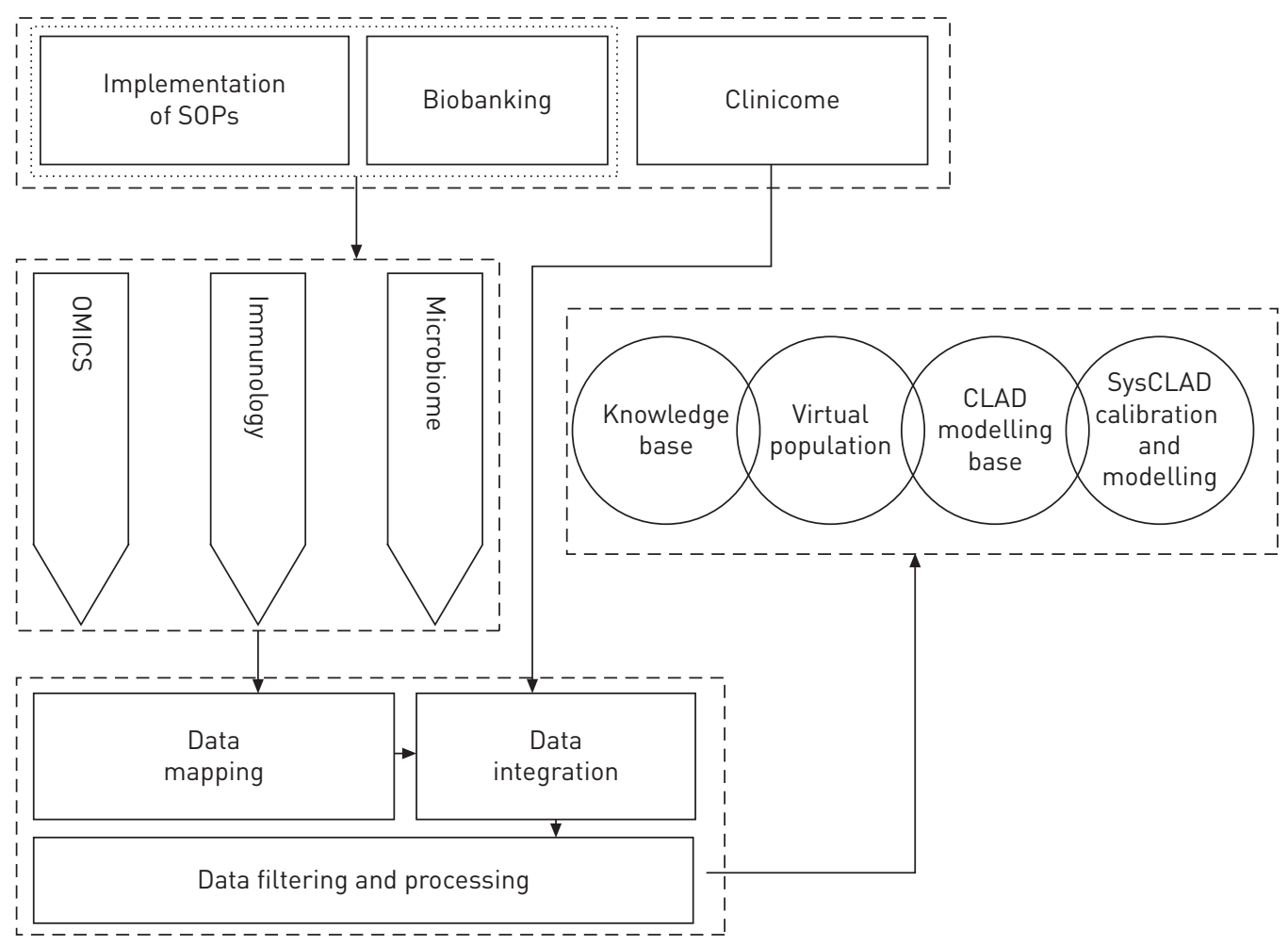

FIGURE 1 Interdependency between project components. SOPs: standardised operating procedures; CLAD: chronic lung allograft dysfunction; SysCLAD: Systems prediction of CLAD.

COLT will guarantee the quality of the data generated in the project and document the collection, storage and management of clinical, biological, and functional data associated with blood collection (table 1) in addition to clinical phenotyping, which includes chest imaging, FEV1, FVC, bronchoalveolar lavage (BAL) analyses (proteomics, microbiote, macrophages subtypes at 6 and 12 months) and bronchial biopsies within the first year post-LT [10]. Similar data collected by the Swiss Transplant Cohort Study (STCS) since 2008 (www.STCS.ch) with 223 patients will be analysed with the COLT patients, resulting in a total of 1050 LT recipients of which 512 and 215 reached 2 and 3 years of follow-up by August 2013, respectively. Prospective analyses of LT recipient lung microbiomes via microRNA sequencing and BAL microbiote sequencing will be carried out to understand whether changes in bacterial communities are a cause or a consequence of CLAD. Recent evidence has revealed that under steady-state conditions the human airways harbour significant microbial communities whose persistence might be crucial to LT success and avoidance of CLAD [11]. In parallel, gene expression analysis of M1 and M2 lung macrophages will be carried out in the airways of individuals following LT to provide important new insights into CLAD, as already seen for kidney recipients [12]. Finally, as a recent study reported that traffic-related air pollution is a major risk factor for both BOS and mortality [13], the corresponding outdoor air pollution level for all LT recipients will be assigned according to their home addresses and through the use of already existing exposure models with high spatial and temporal resolutions. Protocol and SOPs are in open access at http://sysclad.newlab.eu The SysCLAD model will be developed on the basis of a 200 LT-recipients dataset and subsequently validated on a second dataset (fig. 1). The development of predictive multiscale mathematical models of CLAD using expertise in numerical modelling of biological information will allow the prediction of the individual- and population-level risk of CLAD by year 3. Systems biology for disease modelling and treatment, or systems medicine, represents an innovative approach to complex diseases understanding and drug discovery $[14,15]$. It consists of representing all the available knowledge on the disease of interest with a mathematical symbolism allowing generation and testing of hypotheses through computational simulation and experimental validation [14, 15]. A CLAD knowledgebase focused on the two subphenotypes BOS and RAS will start with a macroscopic knowledge model, defining the perimeter of the working area, collecting and assessing all relevant knowledge on CLAD and will contain several physiology based submodels. In parallel, a virtual population of LT recipients will be created by crosschecking epidemiological data with model parameters values and distributions across the knowledge base. The systems biology-driven modelling approach will serve to integrate all the biological components that 
are thought to play a role in the course of the disease process, up to the clinical events, by plugging the disease model into a virtual population. Each virtual patient of the population will be characterised by a vector of descriptors that will serve to compute the biological as well as the environmental parameters involved in the course of the disease. The virtual population will be created from environmental, clinical and molecular vectors, and will be applied to the CLAD physiology based computational model (fig. 1). The final computational model, based on the knowledge model, will be subsequently designed and tested. The CLAD model will be calibrated through the integration of clinical and experimental data according to a minimising criterion to generate a fully operative model for the in silico prediction of CLAD within 3 years post-LT (fig. 1). Intrinsic risk factors related to donor/recipient and/or extrinsic hazards as infections, acute rejections could result in CLAD by different pathways. It requires collections of clinical events and their biological markers to integrate these covariables. The actual challenge is to define a personalised risk to develop CLAD after 1 year before any decline in lung function. Limitations are to collect incomplete and/or improper information and miss these predictions. It is the reason why our database should be continuously upgraded with new cases and their outcomes to refine models and better predict outcomes as soon as possible after lung transplantation.

The SysCLAD signature is expected to improve early prediction of CLAD and cost-effectiveness of LT by enabling effective future personalised interventions. The widespread adoption and implementation of the SysCLAD model has the potential to lead to a marked decrease in healthcare costs, specifically those associated with hospitalisation, medication and the use of laboratory services related to CLAD, and to improve patient outcomes.

\section{Acknowledgements}

We are indebted to Programme Hospitalier de Recherche Clinique 2008 (Paris, France) and Vaincre La Mucoviscidose (Paris, France) in launching the project within the 11 French lung Transplantation centres within Cohort Of Lung Transplantation (COLT), Programme transplantation 2008, PRTP-13, ClinicalTrials.gov Identifier: NCT00980967, Swiss National research found supporting the STCS and in particular the lung transplant section (No 3347CO-108795).

SysCLAD consortium: 14 lung transplantations centres of whom 12 are within COLT (11 French centres plus Brussels), one is in Geneva-Lausanne and one in Zurich, associating surgeons, anaesthetists, intensivists, physicians, research assistants and five SME and/or platforms. COLT centres include Brussels, Belgium: M. Antoine, A. Belhaj, M. Cappello, B. Rondelet, M. Ruiz, Y. Sokolow, F. Vanden Eynden, G. Van Nooten, L. Barvais, J. Berré, S. Brimioulle, D. De Backer, J. Créteur, E. Engelman, I. Huybrechts, B. Ickx, T.J.C. Preiser, T. Tuna, L. Van Obberghe, N. Vancutsem, J-L. Vincent, D. Abramowicz, P. De Vuyst, I. Etienne, F. Féry, F. Jacobs, C. Knoop, J.L. Vachiéry, P. Van den Borne, I. Wellemans; G. Amand, L. Collignon, M. Giroux; Grenoble, France: V. Bach, P-Y. Brichon, P. Chaffanjon, O. Chavanon, A. de Lambert, S. Guigard, A. Pirvu, P. Porcu, R. Hacini; P. Albaladejo, C. Allègre, D. Anglade, D. Bedague, P. Bouzat, E. Briot, O. Carle, M. Casez-Brasseur, D. Colas, G. Dessertaine, M. Durand, J. Duret, M.C. Fèvre, G. Francony, S. Gay, M.R Marino, D. Protar, D. Rehm, S. Robin, M. Rossi-Blancher, L. Saunier, P. Bédouch, A. Boignard, H. Bouvaist, A. Briault, B. Camara, M. Dubuc, E. Honnorat, S. Quêtant, J Maurizi, P. Pavèse, C. Pison, C. Saint-Raymond, N. Wion; C. Chérion; Bordeaux, France: J. Jougon, J.F. Velly, H. Rozé, E. Blanchard, C. Dromer; Lyon, France: O. Jegaden, J-M. Maury, F. Tronc, O. Bastien, C. Flamens; J-F. Mornex, F. Philit, A. Senechal, A. Tiberghien; A. Mezergues, C. Dubois; Paris (Hôpital Européen Georges Pompidou), France: F. Le Pimpec Barthes, A. Bel, P. Mordant, P. Achouh; V. Boussaud; R Guillemain, D Méléard, M.O. Bricourt, B Cholley; V Pezella; Marseille, France: M. Adda, M. Badier, B. Coltey, X.B. D’Journo, S. Dizier, C. Doddoli, N. Dufeu, H. Dutau, JM. Forel, JY. Gaubert, C. Gomez, M. Leone, A. Nieves, B. Orsini, L. Papazian L, M. Reynaud-Gaubert, A. Roch, JM. Rolain, V. Secq, P. Thomas, D. Trousse; Nantes, France: O. Baron, P. Lacoste, C. Perigaud, J.C. Roussel; I. Danner, A Haloun A. Magnan, A Tissot; T. Lepoivre, M. Treilhaud; K BotturiCavaillès, Sophie Brouard, Richard Danger, Mallory Pain, P-J. Royer; Paris (Hôpital Marie Lanelongue), France: P. Dartevelle, E. Fadel, S. Mussot, D. Fabre, O. Mercier; P. Viard, S. François; J. Cerrina, P. Hervé, J. Le Pavec, F. Le Roy Ladurie; Paris (Hôpital Bichat), France: Y. Castier, P. Cerceau, F. Francis, G. Lesèche; N. Allou, P. Augustin, S. Boudinet, M. Desmard, G. Dufour, P. Montravers, O. Brugière, G. Dauriat, G. Jébrak, H. Mal, A. Marceau, A-C. Métivier, G. Thabut, B. Ait Ilalne; Strasbourg, France: P. Falcoz, G. Massard, N. Santelmo, G. Ajob, O. Collange O. Helms, J. Hentz, A. Roche, B. Bakouboula, T. Degot, A. Dory, S. Hirschi, S. Ohlmann-Caillard, L. Kessler R. Kessler, A. Schuller, K. Bennedif, S. Vargas; Suresnes, Paris: P. Bonnette, A. Chapelier, P. Puyo, E. Sage, J. Bresson, V. Caille, C. Cerf, J. Devaquet, V. Dumans-Nizard, ML. Felten, M. Fischler, AG. Si Larbi, M. Leguen, L. Ley, N. Liu, G. Trebbia; S. De Miranda, B. Douvry, F. Gonin, D. Grenet, A.M. Hamid, H. Neveu, F. Parquin, C. Picard, A. Roux, M. Stern, F. Bouillioud, P. Cahen, M. Colombat, C. Dautricourt, M. Delahousse, B. D’Urso, J. Gravisse, A. Guth, S. Hillaire, P. Honderlick, M. Lequintrec, E. Longchampt, F. Mellot, A. Scherrer, L. Temagoult, L. Tricot; M. Vasse, C. Veyrie, L. Zemoura; Toulouse, France: J. Berjaud, L. Brouchet, M. Dahan, F. Le Balle, O. Mathe; H. Benahoua, A. Didier, A.L. Goin, M. Murris; L. Crognier, O. Fourcade; Genève-Lausanne, Switzerland: T. Krueger, H.B. Ris, J.H. Robert, J. Wellinger; J-D. Aubert, C. Blanc L.P. Nicod, B.J. Marsland, T. Rochat, P. Soccal; Ph. Jolliet, A Koutsokera, C. Marcucci, O Manuel; M. Chollet, F. Gronchi; Zurich, Switzerland: S. Hillinger, I. Inci, P. Kestenholz, W. Weder; M. Bechir, M. Zalunardo; C. Benden, A. Boehler, B. Isenring, M. Schuurmans, G.M. Tini; A. Brucher, T. Fehr, A. Gaspert, D. Holzmann, N. Müller, S. Nicca, C. Schmid.

Biomax Informattics AG, Planegg, Germany: D. Meier; Finovatis, Lyon France: D. Koubi; GATC Biotech AG, Konstanz, Germany: B. Wahl; Novasdicovery, Lyon France: G. Olivera-Botello; Prométhée Proteomics Platform, Grenoble, France: C. Trocmé, B. Toussaint, S. Bourgoin-Voillard, M. Séve; Université Joseph Fourier, Inserm U823, Grenoble, France: M. Benmerad, R. Slama; European Institute for Systems Biology and Medicine, Lyon, France: C. Auffray, D. Charron, C. Pison. 


\section{References}

1 Christie JD, Edwards LB, Kucheryavaya AY, et al. The Registry of the International Society for Heart and Lung Transplantation: 29th adult lung and heart-lung transplant report-2012. J Heart Lung Transplant 2012; 31: 1073-1086.

2 Sato M, Waddell TK, Wagnetz U, et al. Restrictive allograft syndrome (RAS): a novel form of chronic lung allograft dysfunction. J Heart Lung Transplant 2011; 30: 735-742.

3 Verleden GM, Raghu G, Meyer KC, et al. A new classification system for chronic lung allograft dysfunction. J Heart Lung Transplant 2013 [In press DOI: 10.1016/j.healun.2013.10.022].

4 Wolfe RA, Roys EC, Merion RM. Trends in organ donation and transplantation in the United States, 1999-2008. Am J Transplant 2010; 10: 961-972.

5 Roedder S, Vitalone M, Khatri P, et al. Biomarkers in solid organ transplantation: establishing personalized transplantation medicine. Genome Med 2011; 3: 37.

6 Roedder S, Kimura N, Okamura H, et al. Significance and suppression of redundant IL17 responses in acute allograft rejection by bioinformatics based drug repositioning of fenofibrate. PLoS One 2013; 8: e56657.

7 Goldfarb-Rumyantzev AS. Personalised medicine, prediction of outcome in kidney transplant. Am J Kidney Dis 2010; 56: 817-819.

8 Poste G. Biospecimens, biomarkers, and burgeoning data: the imperative for more rigorous research standards. Trends Mol Med 2012; 18: 717-722.

9 Sato M, Ohmori-Matsuda K, Saito T, et al. Time-dependent changes in the risk of death in pure bronchiolitis obliterans syndrome (BOS). J Heart Lung Transplant 2013; 32: 484-491.

10 Wheelock CE, Goss VM, Balgoma D, et al. Application of 'omics technologies to biomarker discovery in inflammatory lung diseases. Eur Respir J 2013; 42: 802-825.

11 Willner DL, Hugenholtz P, Yerkovich ST, et al. Reestablishment of recipient-associated microbiota in the lung allograft is linked to reduced risk of bronchiolitis obliterans syndrome. Am J Respir Crit Care Med 2013; 187: 640-647.

12 Hutchinson JA, Riquelme P, Sawitzki B, et al. Cutting edge: immunological consequences and trafficking of human regulatory macrophages administered to renal transplant recipients. J Immunol 2011; 187: 2072-2078.

13 Nawrot TS, Vos R, Jacobs L, et al. The impact of traffic air pollution on bronchiolitis obliterans syndrome and mortality after lung transplantation. Thorax 2011; 66: 748-754.

14 Billy F, Ribba B, Saut O, et al. A pharmacologically based multiscale mathematical model of angiogenesis and its use in investigating the efficacy of a new cancer treatment strategy. J Theor Biol 2009; 260: 545-562.

15 Boissel JP, Ribba B, Grenier E, et al. Modelling methodology in physiopathology. Prog Biophys Mol Biol 2008; 97: 28-39. 